\title{
Practice and Exploration on the Construction of Supervisor Team for Masters of Medicine under the Mode of Double Track Integration
}

\author{
Bo Ling*, Yan Li*, Liqing Li, Yan-E Zhou, Longjian Huang, Xiaoqing Wen, Xianjiu Liao\#, \\ Qianli Tang\#
}

Youjiang Medical University for Nationalities, Baise, China

Email: "lxj2006910@163.com, ${ }^{* h t m g x 919 @ 163 . c o m ~}$

How to cite this paper: Ling, B., Li, Y., Li, L. Q., Zhou, Y., Huang, L. J., Wen, X. Q., Liao, X. J., \& Tang, Q. L. (2021). Practice and Exploration on the Construction of Supervisor Team for Masters of Medicine under the Mode of Double Track Integration. Advances in Applied Sociology, 11, 244-250.

https://doi.org/10.4236/aasoci.2021.115021

Received: April 21, 2021

Accepted: May 10, 2021

Published: May 13, 2021

Copyright $\odot 2021$ by author(s) and Scientific Research Publishing Inc. This work is licensed under the Creative Commons Attribution International License (CC BY 4.0).

http://creativecommons.org/licenses/by/4.0/

\begin{abstract}
Objective: Explore the new system for constructing a supervisor team of masters of medicine under the mode of double track integration. Methods: Based on the current construction of supervisor team for masters of medicine under the mode of double track integration, this paper tries to find proper methods to improve the construction of supervisor team for masters of medicine proceed from the discipline development, academic level, clinical and scientific research system, supervisor teaching arrangement, and transformation ability of science and technology. Results: Under the mode of double track integration, five aspects of the supervisor training system, selection system, supervisor group system, course leader system, and industry-study-research mode need to be integrated efficiently, thereby providing strong support for the development of masters of medicine supervisor team. Conclusion: In view of the current construction of the supervisor team for masters of medicine under the mode of double track integration, further integration will provide a feasible direction for the construction of the supervisor team for masters of medicine.
\end{abstract}

\section{Keywords}

Double Track Integration, Masters of Medicine, Supervisor Team Construction, Current Situation, Solution

\section{Introduction}

As an important part of higher medical education in China, the training of mas-

${ }^{\star}$ These authors contributed equally to this work.

${ }^{*}$ Corresponding authors. 
ters of medicine postgraduates shoulders the mission of cultivating high-level medical talents (Huang, Xu, Pang, \& Tang, 2020). In order to further standardize and enhance the quality of masters of medical training, China launched the "Double Track Integration" masters of the medical training system in 2014, which focuses on the standardized training of students' clinical skills and highlights the cultivation of scientific research innovation to realize the overall training of doctors who can "treat the sick" and "research the sick" as a whole (Xiao, 2020). Under the mode of double track integration, masters of medicine must complete at least 33 months of clinical rotation learning and scientific research content with high quality and high level at the same time (Wang, Zeng, Huang, \& Wan, 2020). The high-intensity and high-level training of masters of medicine has become a challenge that various universities and colleges have to face. Among them, the level of supervisor teams is an effective method to solve the challenge in medical colleges and universities, as well as a key to the quality of masters of medical training. Therefore, focusing on the current situation of supervisor team for masters of medicine under the mode of double track integration, it has become one of the mainstream directions of education and teaching reform in medical colleges to find proper solutions from the problems and difficulties, and to boost the construction of supervisor team for masters of medicine.

\section{Current Situation of Supervisor Team for Masters of Medicine}

\subsection{Unbalanced Discipline Development}

The imbalance of discipline development is one of the common problems in the discipline system of medical colleges. Preponderant disciplines usually accumulate a large amount of foundation in the platform, discipline system, funding guarantee and supervisor team with a certain popularity and reputation in both domestic and foreign professional fields (Duan, Hu, Duan, \& Tian, 2017). However, the weak disciplines usually start late and develop for a short time with inadequate system construction, especially the problems such as weak teacher resources, which cause the training of masters of medicine far from satisfactory. The latest research points out (Yang \& Luo, 2020) that the preponderant disciplines are not only superior to weak disciplines in the training quality of masters of medicine, but also have a powerful advantage in the source of students. Preponderant disciplines are overcrowded with applicants, while supervisors in some weak disciplines are unable to recruit professional masters. However, the quality of masters of medical training and the source of students is the foundation for discipline development. Therefore, to accelerate the discipline development, especially to improve the problem of weak teacher resources in weak disciplines, is the key to ensure the source of students and training quality of masters of medicine.

\subsection{Big Gap between Academic Levels}

In the construction of supervisor teams in medical colleges, there is a significant 
gap between the academic level of different supervisors. The gap of academic level is mainly reflected in the three dimensions of scientific research tasks, funds and achievements, which are also the key guarantee to ensure the quality of masters of medical training. The overall level of supervisors in medical colleges and universities is high, and some of them have been funded for a long time in national, provincial and other projects, which provides sufficient projects and funding guarantee for student training; however, a few supervisors have not received any project funding within 3 to 5 years, which leads to difficulties in student training (Liu, Yi, \& Fu, 2021). In the aspect of achievement, the achievements of some supervisors are in the leading position at home and abroad, which can provide a clear technical basis and direction for the cultivation of students; however, there is also a phenomenon that a few supervisors have not published high-level results within 3 to 5 years, which cannot provide strong support for masters of medical training. Therefore, the overall improvement of the academic level of the teaching staff has become one of the core directions of the construction of masters of medicine supervisor team.

\subsection{Hard to Reconcile Clinical and Scientific Research}

The front-line clinical doctors usually work as the masters of medicine supervisors. The clinical front-line experts undertake the dual tasks of clinical teaching and scientific research guidance, thereby ensuring the training quality of masters of medicine. The first-line clinical masters of medicine supervisors are usually busy with clinical diagnosis and treatment, but they can help students gain rich clinical knowledge and experience through clinical teaching; however, there is no more time and energy in scientific research guidance to fully satisfy the cultivation of students' scientific research innovation ability (Bai, Li, \& Huang, 2019). Therefore, it is a difficult problem for masters of medicine supervisors to reconcile clinical and scientific research, which is also one of the main contents of the education and teaching reform of postgraduate in medical colleges.

\subsection{Unreasonable Distribution of Teaching Time of Supervisor}

The courses of masters of medicine are the basis of its follow-up clinical study and scientific research. However, in the current theoretical curriculum system of medical colleges, the basic medicine teachers usually undertake the basic theory courses; while the clinical medicine teachers undertake the clinical theory courses. As a core professional course, the proportion of front-line clinical experts in the clinical theory curriculum system is not high, but young teachers are the main body to undertake it (Jiang, 2021). However, the problems of lack of clinical and scientific research experience and limited cognitive level of young teachers are still prominent, which cause poor learning of masters of medicine core course. Therefore, it is an effective way to consolidate the clinical and scientific research foundation of students to arrange the professional courses of masters of medicine supervisors reasonably. 


\subsection{Transformation Ability of Science and Technology Needs to Be Improved}

The transformation of science and technology has become a new important part of the academic level of masters of medicine supervisors. Masters of medicine supervisors usually come from front-line clinical experts, whose research contents have clinical application potential and can solve clinical difficulties. But the transformation of achievements needs the participation of universities and colleges, hospitals, research institutes and enterprises. And during the transformation of science and technology, masters of medicine actively participate in the whole link of the project, which can play an important role in promoting the innovation ability (Li \& Wang, 2020). Therefore, it is one of the important tasks for medical colleges and universities to promote the transformation of science and technology with multi-participation.

\section{New Measures for Constructing Supervisor Team of Masters of Medicine}

\subsection{Strengthen Perfect Supervisor Training System and Accelerate the Development of Weak Disciplines}

Among the unbalanced factors of discipline development, the weak teaching staff of weak discipline is the core problem that must be solved. Strengthening perfect supervisor training system is the key link in the effective solution to the problem of weak teaching staff. Based on the effective separation of the weak links of teaching staff, it can be found that professional and scientific research skills need to be improved which are the two most important elements (Chang, Zhang, Cui, Zhu, Zhou, Du, \& Ding, 2021). In the process of clinical professional skills, medical colleges can select and send supervisors to excellent hospitals at home and abroad for further study, combined with lectures and training of clinical experts from outside the school, thus improving the clinical level of the teaching staff of weak disciplines. In the part of scientific research, medical colleges can adopt a combination of regular academic reports, academic lectures, domestic and foreign visits and other methods to improve the scientific research level of the teaching staff (Zhang \& Li, 2020). At the same time, medical colleges also need to develop a feedback mechanism for the supervisor training to effectively adjust the training program, lead to true adaptation to the improvement of the level of the teaching staff. Based on clinical and scientific research, the combination of various training systems and the feedback mechanism will further strengthen the supervisor training system and provide support for the development of teachers.

\subsection{Raise the Threshold of Supervisor Selection}

According to the relevant regulations of the Academic Degrees Committee of the State Council, the selection and listing of supervisors are carried out by various training institutions through own selection standards and verification ac- 
cording to their construction, development and educational needs. Therefore, different medical colleges are not completely same in the selection standards of masters of medicine supervisors, and some universities and colleges have not changed for many years, so it is impossible to truly select outstanding talents to enrich the team of masters of medicine supervisor (Ye \& Yang, 2019). According to the national regulations and industry changes, it has become one of the mainstream trends to supplement the selection standards of supervisors. For masters of medicine supervisor with both ability and integrity, first of all they should have the noble sentiment of loving the party and the country, as well as the feeling of loving education; in terms of talent, they must have excellent clinical skills and high-level research results (Huangfu, Huang, \& Du, 2017). Therefore, based on the two dimensions of ability and integrity, the construction of systematic selection standard will effectively select high-level supervisor team and provide a key guarantee for the masters of medical training.

\subsection{Trial Supervisor Group System to Take Full Advantage of Clinical and Scientific Research}

Facing the problem of reconciling clinical and scientific research, the supervisor group system has become one of the current solutions (Yuan, Hou, Chen, \& Bai, 2015). Supervisor group system is a method in which clinical supervisors are the main body, and other supervisors are added to the training system to jointly cultivate students. In China, double supervisor system is the main form (Cui, Lyu, \& Chen, 2017). While clarifying the main responsibility of clinical supervisor training, the supervisor group system introduces the scientific research resources of teachers from multiple departments, such as basic medicine and experimental center, and organically combines the clinical and scientific research, so that the cultivation of students can truly reconcile the clinical and scientific research. Therefore, the implementation of the supervisor group system will achieve effectively the overall goal of "doctors who can treat the sick and research the sick" of masters of medicine.

\subsection{Course Leader System to Improve the Quality of Core Professional Course}

Core professional courses are the basis of clinical and scientific research training for students. The unsound curriculum system and the low participation of experts are the key factors that lead to the unsolid foundation and weak innovation ability of masters of medicine (Liu, Liang, Zhang, \& Cheng, 2021). While clarifying the main responsibility of the curriculum construction, the course leader system improves the participation of experts, which has become one of the methods attempted by medical colleges (Liu, 2015). The course leader system refers to that, firstly, in the teaching team of the core professional courses, experts are selected as the course leader through the method of grading according to the three dimensions of clinical, scientific research and teaching level and combining the election; and at the same time, the experts organize the supervisors and 
the teaching teams to jointly formulate the teaching and training programs, and improve the professional course teaching workload of experts and supervisors, thereby ensuring the leading role of experts and masters of medicine supervisors, and give full play to their participation in courses, and then maintain the quality of core professional courses.

\subsection{Introduction of Industry-Study-Research Mode to Improve Transformation Ability of Science and Technology}

During the transformation of science and technology, industry-study-research mode is one of the mainstream ways. Industry-study-research mode can effectively integrate the resources of universities and colleges, hospitals, research institutes and enterprises. Especially in the transformation of scientific research achievements of masters of medicine supervisors, the scientific research institutes can undertake the detection and verification of achievements, and the enterprises can be responsible for the small-scale test of achievements to finished design, thus realizing the effective complementation of resources and achieving the goal of scientific and technological achievements to finally serve clinical (Shi, 2020). At the same time, students can participate in the whole process of the industry-study-research project, thereby cultivating systematically from clinical, scientific research and application, and improving the level of clinical skills and scientific research innovation of masters of medicine.

In conclusion, under the mode of double track integration, medical colleges and universities can deepen reform in five dimensions: strengthening perfect supervisor training system, raising the threshold of supervisor selection, trial supervisor group system, implementing course leader system, and introducing the industry-study-research mode, thus promoting the construction of masters of medicine supervisor team.

\section{Fund Program}

Innovation Project of Guangxi Postgraduate Education (Project No. JGY2020170, JGY2019161, JGY2021219); construction project of case bank for professional degree postgraduate teaching in Youjiang Medical University for Nationalities (Project Name: Case Bank Construction of Surgery Teaching).

\section{Conflicts of Interest}

The authors declare no conflicts of interest regarding the publication of this paper.

\section{References}

Bai, J., Li, G. R., \& Huang, J. Q. (2019). Status Report and Analysis of the Relationship Between Full-time Medical Graduate Students and Their Mentors-Based a Survey Conducted at a "Project 211" University. Journal of Adult Education College of Hebei University, 21, 111-119.

Chang, X. H., Zhang, L. Z., Cui, Y. L., Zhu, G., Zhou, Y. J., Du, F. L., \& Ding, H. (2021). 
On the Construction of Clinical Teachers in Medical Colleges and Universities under the Background of "Double Tops". Journal of Traditional Chinese Medicine Management, 29, 22-24.

Cui, L. J., Lyu, Y., \& Chen, Y. B. (2017). Problems in Medical Postgraduate Education and the Role of Tutors in China. Chinese Journal of Laboratory Diagnosis, 21, 189-191.

Duan, Z. J., Hu, C. Q., Duan, G. F., \& Tian, W. H. (2017). Comparison and Reflection of Different Accreditation Index Systems for Medical Clinical Centers and Key Disciplines. Hospital Administration Journal of Chinese People's Liberation Army, 24, 138-140, 164.

Huang, L. F., Xu, Y., Pang, G. F., \& Tang, G. L. (2020). Research on Standardization of Medical Specialized Master Training Based on "Double Track Integration" Model. Guangxi Education, No. 3, 117-119.

Huangfu, M. F., Huang, N., \& Du, W. J. (2017). Discussion on the Construction of Postgraduate Tutor Team in Higher Medical Education. Journal of Medical Postgraduates, 30, 1318-1321.

Jiang, X. (2021). Cultivation Factors of Medical Postgraduate Education from the Perspective of Core Literacy. Medical Education Management, 7, 34-37, 41.

Li, G. X., \& Wang, Y. N. (2020). Opportunities and Challenges for Doctors in the Transformation of Medical Science and Technology Achievements in China. Chinese Journal of Gastrointestinal Surgery, 23, 545-549.

Liu, J. M., Liang, S. J., Zhang, G. C., \& Cheng, M. (2021). Practice and Effect Analysis of Integration of Medical Courses in Local Medical Colleges. Medical Education Research and Practice, 29, 32-36.

Liu, N., Yi, Z. J., \& Fu, Y. R. (2021). Analysis of the Status Quo of Tutors' Quality Based on the Cultivation of Medical Postgraduates' Innovative Ability and the Promotion Strategies. Health Vocational Education, 39, 14-16.

Liu, Q. (2015). Practice and Exploration on the Construction of Teaching Management Mode with Course Leader System as Unit in Colleges and Universities. Health Vocational Education, 33, 11-12.

Shi, J. D. (2020). Exploration on the Mode of Talent Training in the Integration of Industry-University-Research in Medical Colleges and Universities-A Case Study of Hebei Medical University. Technology Wind, No. 8, 213-214.

Wang, X. Y., Zeng, W., Huang, Y., \& Wan, X. H. (2020). Exploration and Practice of "Five Early" Model for Professional Master's Degree Graduate Student in Clinical Medicine. Chinese Journal of Evidence-Based Medicine, 20, 214-220.

Xiao, Y. T. (2020). A Study on the Effect and Problems of Clinical Medicine Professional Master's Degree based on the Combined Traning in the Standardized Residents Traning in Hospital. Guangzhou: Southern Medical University.

Yang, C., \& Luo, A. L. (2020). Reflection on the Training of Clinical and Scientific Compound Physician in National Key Disciplines of Research Hospitals in China. Education Modernization, 7, 8-10.

Ye, X. G., \& Yang, Y. (2019). Introduction of the Role of Tutor in Professional Degree Postgraduates of Clinical Medicine under the System of Standardized Residents Training. Continuing Medical Education, 33, 61-63.

Yuan, K., Hou, Y. B., Chen, D. L., \& Bai, Y. (2015). Research on Tutor Group System of Postgraduate Students and Degree Cultivation Model of Clinical Medicine Specialty. Chongqing Medicine, 44, 4300-4301.

Zhang, K., \& Li, X. M. (2020). Reflection on the Present Situation of Standardized Training for Resident Doctors in China. Chinese Journal of Medical Education Research, 19, 1447-1450. 